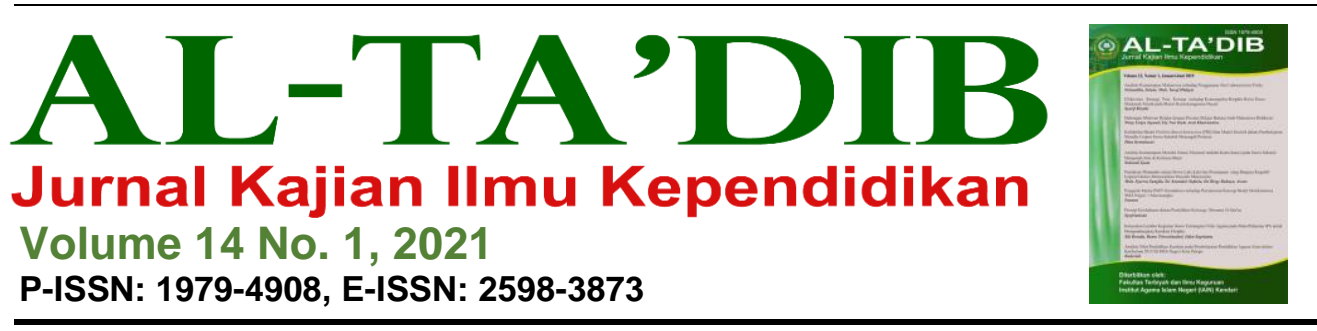

\title{
Strategi Kepala Sekolah dalam Pelaksanaan Ujian Nasional Berbasis Komputer (UNBK) di Sekolah Menengah Pertama
}

\author{
Nurdin $^{1}$, Laode Anhusadar ${ }^{2}$, Herlina $^{3}$, Sitti Nurhalimah $^{4}$ \\ ${ }^{1}$ Institut Agama Islam Negeri Kendari, Indonesia, Email: nurdinkarim@gmail.com \\ ${ }^{2}$ Institut Agama Islam Negeri Kendari, Indonesia, Email: sadar.wanchines@gmail.com \\ ${ }^{3}$ Institut Agama Islam Negeri Kendari, Indonesia, Email: herlinalin@ gmail.com \\ ${ }^{4}$ Institut Agama Islam Negeri Kendari, Indonesia, Email: imahnurhalimah12@gmail.com
}

\author{
ARTICLE INFO \\ Keywords: \\ computer-based national \\ exam; exam; principal; \\ strategy \\ How to Cite: \\ Nurdin, Anhusadar, L., \\ Herlina, \& Nurhalimah, S. \\ (2021). Strategi kepala \\ sekolah dalam pelaksanaan \\ ujian nasional berbasis \\ computer (UNBK) di \\ sekolah menengah \\ pertama. Al-Ta'dib: Jurnal \\ Kajian Ilmu Kependidikan, \\ 14(1), 1-13.
}

\begin{abstract}
This qualitative case study aims to review and analyze the condition of the information and communication technology (ICT) facilities for the implementation of the computer-based national examination (UNBK), the principal's strategies in implementing $U N B K$, and the obstacles in implementing UNBK at one of junior high schools in Kota Kendari, Southeast Sulawesi, Indonesia. Data were collected by interview, observation and documentation. The result of data analysis revealed the lack of facilities for the implementation of UNBK in the school. The principal's strategies in implementing UNBK in the school cover various aspects, such as facilities and infrastructure, human resources, and pupil affairs. Two obstacles emerged i.e., technical and non-technical.
\end{abstract}


INFORMASI ARTIKEL

Kata Kunci:

Kepala sekolah; strategi; ujian; UNBK

\section{Cara Mensitasi:}

Nurdin, Anhusadar, L., Herlina, \& Nurhalimah, S. (2021). Strategi kepala sekolah dalam pelaksanaan ujian nasional berbasis computer (UNBK) di sekolah menengah pertama. Al-Ta'dib: Jurnal Kajian Ilmu Kependidikan, 14(1), 1-13.

\begin{abstract}
ABSTRAK
Penelitian studi kasus ini bertujuan untuk mengkaji dan menganalisis kondisi sarana teknologi informasi dan komunikasi (TIK) untuk pelaksanaan ujian nasional berbasis komputer (UNBK), strategi kepala sekolah dalam pelaksanaan UNBK, serta kendala dalam pelaksanaan UNBK di salah satu sekolah menengah pertama di Kota Kendari, Sulawesi Tenggara, Indonesia. Data dikumpulkan melalui wawancara, observasi dan dokumentasi. Hasil analisis data menunjukkan bahwa kondisi fasilitas komputer untuk pelaksanaan UNBK di sekolah belum memadai. Strategi kepala sekolah dalam pelaksanaan UNBK meliputi strategi di bidang sarana dan prasarana, sumber daya manusia, dan kesiswaan. Ada dua kendala dalam pelaksanaan UNBK yang mengemuka, yaitu kendala teknis dan non teknis.
\end{abstract}

\section{Pendahuluan}

Pendidikan merupakan salah satu sarana untuk menciptakan sumber daya manusia yang berkualitas. Sumber daya manusia yang berkualitas akan membangun suatu negara sehingga dapat meningkatkan kualitas suatu bangsa di era digital (Wirawan, Indrawati, \& Rahmanto, 2017). Salah satu tantangan dalam pendidikan di abad ini yaitu membangun keterampilan di bidang teknologi informasi dan komunikasi. Teknologi ini penting karena akan membantu mengembangkan semua jenis keterampilan berpikir mulai dari tingkat yang paling mendasar hingga tingkat keterampilan berpikir kritis (Sampebua \& Membala, 2018). Oleh karena itu, dalam pendidikan modern, pendidikan dituntut untuk mampu mengintegrasikan teknologi informasi dan komputer dalam setiap lini pendidikan.

Pada tahun pelajaran 2014/2015, Kementerian Pendidikan dan Kebudayaan mengeluarkan kebijakan baru terkait penyelenggaraan ujian nasional (UN) bahwa ujian nasional dapat dilaksanakan dengan dua cara. Pertama, ujian nasional dilaksanakan secara tertulis atau paper based test (PBT). Kedua, ujian nasional dapat dilaksanakan dengan mekanisme berbasis komputer atau yang dikenal dengan computer based test (CBT). Perbedaan kedua metode pelaksanaan ujian nasional tersebut hanya terletak pada aspek teknis dalam pelaksanaan saja, yang meliputi penggandaan dan pendistribusian soal UN oleh pemerintah dan pengerjaan soal UN oleh siswa (Pranata, Pitoewas, \& Nurmalisa, 2017). Sejak ditetapkan dalam kebijakan pemerintah, pelaksanaan ujian nasional berbasis komputer (UNBK) telah 
menjadi keharusan untuk diterapkan di sekolah sebagai tolok ukur pencapaian peserta didik pada mata pelajaran tertentu yang dilaksanakan sesuai waktu yang ditentukan dengan bantuan fasilitas teknologi dan informasi komputer. Akan tetapi, masih terbatas jumlah sekolah penyelenggara UNBK karena tidak semua sekolah memenuhi persyaratan yang telah ditentukan.

Penelitian yang fokus pada implementasi UNBK telah banyak dilakukan (Aden, Basir, \& Kusdaniyama, 2020; Firmansyah, 2018; Harmiyuni \& Sailan, 2016; Hartina, 2018; Meita \& Fatoni, 2020; Murtadlo, Jazuli, \& Catur Murti, 2019; Pakpahan, 2016; Pernamawati, Kritiawan, \& Fitria, 2021; Tamala, 2019). Penelitian sebelumnya telah mengangkat berbagai isu, termasuk bagaimana pelaksanaan UNBK (Pernamawati, dkk., 2021; Simbolon, Kadir, \& Nasution, 2019), kesiapan pelaksanaan ujian nasional berbasis komputer bagi sekolah dan siswa (Meita \& Fatoni, 2020), strategi kepala sekolah dalam meningkatkan kualitas guru dan siswa untuk jenis soal UNBK (Negara, Santosa, \& Bahri, 2017; Nirmala, 2013; Sampebua \& Membala, 2018), manfaat dan tantangan dalam berbagai model UNBK (Pakpahan, 2016; Rahmania, Budiono, Soenaryo, Syakur, \& Tinus, 2020; Retnawati, Hadi, Nugraha, Arlinwibowo, Sulistyaningsih, Djidu, Apino, \& Iryanti, 2017)), dan evaluasi pelaksanaan UNBK (Pernamawati, dkk., 2021; Rusmawati, Suryana, \& Harapan, 2020). Akan tetapi, penelitian yang fokus menginvestigasi strategi yang dilakukan kepala sekolah dalam pelaksanaan UNBK di sekolah masih kurang dieksplorasi (lihat Tamala, 2019). Oleh karena itu, penelitian ini bertujuan untuk mengisi gap tersebut dengan fokus penelitian yang menekankan pada strategi kepala sekolah dalam pelaksanaan UNBK di salah satu sekolah di Kota Kendari, Sulawesi Tenggara.

\section{Metode Penelitian}

Penelitian ini dilakukan dengan pendekatan studi kasus yang bermaksud untuk memahami fenomena yang terjadi pada sekelompok subjek penelitian dalam suatu entitas (Yin, 2018). Pengumpulan data dilakukan melalui teknik observasi, wawancara dan studi dokumentasi. Lokasi penelitian ini bertempat di salah satu sekolah menengah pertama negeri di Kota Kendari, Sulawesi Tenggara, Indonesia. Sekolah menengah pertama ini merupakan salah satu sekolah favorit di kalangan masyarakat dengan tingkat kualitas dan kuantitas peserta didik yang cukup tinggi. Antusiasme peserta didik untuk dapat bersekolah di sekolah ini cukup tinggi. Hal ini terbukti dengan banyaknya 
pendaftar yang mengikuti tes pada pelaksanaan pendaftaran siswa baru. Pada tahun ajaran 2016/2017, sekolah ini ditunjuk oleh Dinas Pendidikan, Pemuda dan Olahraga setempat dan dinyatakan telah mampu untuk melaksanakan ujian nasional berbasis komputer (UNBK) untuk pertama kalinya. Hal tersebut menjadikan sekolah ini sebagai salah satu dari sepuluh sekolah yang melaksanakan ujian nasional berbasis komputer pada jenjang sekolah menengah pertama negeri atau swasta pada tahun 2017.

Informan utama dalam penelitian ini adalah kepala sekolah, wakil kepala sekolah bidang sarana dan prasarana, teknisi dan proktor UNBK, siswa dan orang tua siswa. Data yang dikumpul melalui observasi, wawancara, dan dokumentasi dianalisis melalui tahapan reduksi data, display data dan penarikan kesimpulan (Miles, Huberman, \& Saldana, 2014). Triangulasi dilakukan dengan cara triangulasi teknik, sumber dan waktu.

\section{Hasil dan Pembahasan}

\subsection{Kondisi Sarana IT untuk Pelaksanaan UNBK}

Hasil analisis data dalam penelitian studi kasus ini menunjukkan bahwa dalam menerapkan UNBK, sekolah bersangkutan mengupayakan persiapan dan pemenuhan kebutuhan sarana dan prasarana agar UNBK dapat terlaksana dengan lancar. Akan tetapi, kesiapan dari pihak sekolah belum didukung sarana yang memadai. Sekolah ini belum memiliki perangkat server berupa sebuah sistem komputer yang menyediakan jenis layanan tertentu dalam sebuah jaringan komputer (web). Pelaksanaan UNBK untuk pertama kalinya ini pun memancing pro dan kontra dari orang tua siswa.

Tabel 1. Profil Fasilitas Komputer untuk UNBK

\begin{tabular}{cc}
\hline Tahun Pelajaran & Jumlah Komputer \\
\hline $2016 / 2017$ & 20 unit \\
$2017 / 2018$ & 40 unit \\
$2018 / 2019$ & 40 unit \\
$2019 / 2020$ & 45 unit \\
\hline
\end{tabular}

Tabel 1 menunjukkan bahwa pada tahun 2017 sekolah ini hanya memiliki 20 unit komputer, sedangkan siswa yang mengikuti ujian nasional berjumlah 413 orang. Jumlah tersebut merupakan peserta yang terbanyak dalam pelaksanaan UNBK pada tahun 2017. Minimnya bimbingan teknis 
bagi siswa dalam mengoperasikan komputer juga menyebabkan kendala dalam teknis pelaksanaan ujian. Kemudian, pada pelaksanaan UNBK pada tahun 2017/2018, sekolah ini dilengkapi dengan 20 unit komputer dari pemerintah, sehingga satu ruangan komputer berisi empat puluh unit komputer untuk pelaksanaan UNBK pada tahun 2017/2018 dan 2018/2019.

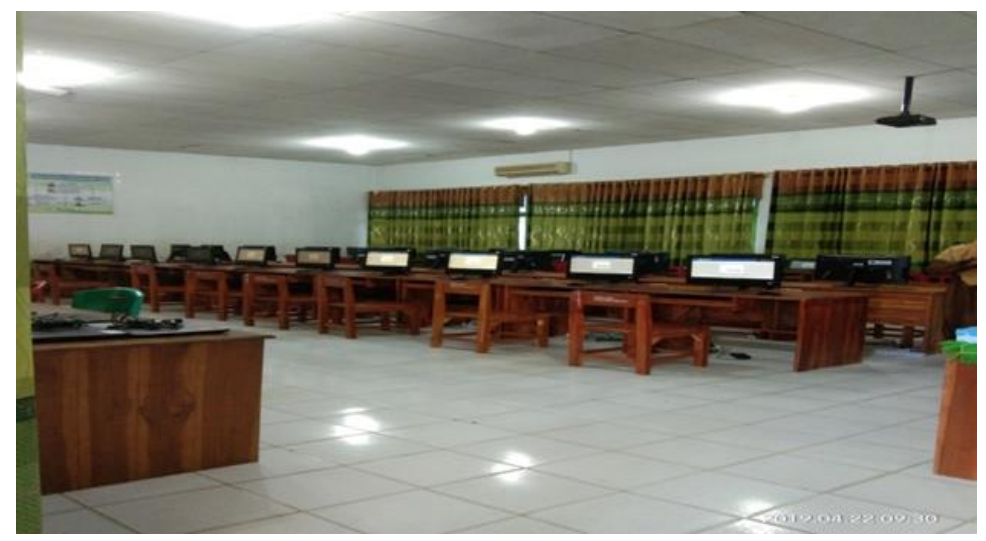

Gambar 1. Fasilitas di Laboratorium Komputer

Untuk pelaksanaan UNBK pada tahun 2019, sekolah sudah memiliki 45 unit komputer dan telah memenuhi satu ruangan untuk pelaksanaan UNBK di laboratorium komputer, namun jumlah tersebut masih kurang memadai sebab sekolah masih membutuhkan kurang lebih 120 unit komputer lagi agar bisa memenuhi tiga ruangan lainnya yang digunakan sebagai ruang pelaksanaan UNBK dengan jumlah peserta ujian setiap tahunnya sekitar 400an peserta. Gambaran sarana ini menunjukkan bahwa sekolah ini masih belum memenuhi persyaratan untuk menyelenggarakan UNBK.

\subsection{Strategi Kepala Sekolah dalam Menerapkan Ujian Nasional Berbasis Komputer}

Hasil analisis data dalam penelitian ini menunjukkan bahwa dalam pelaksanaan UNBK di sekolah ini, kepala sekolah melakukan beberapa persiapan. Beliau menerapkan beberapa strategi berupa strategi sarana dan prasarana, strategi sumber daya manusia, dan dan strategi kesiswaan.

\section{Strategi Bidang Sarana dan Prasarana}

Proses perencanaan sarana dan prasarana UNBK adalah pemenuhan kriteria persyaratan infrastruktur UNBK oleh sekolah. Dalam pelaksanaan 
UNBK pihak sekolah melakukan persiapan sarana dan prasarana yang meliputi penyiapan komputer server, jaringan internet, hardware pendukung lain serta ruangan. Proses berikutnya adalah pengadaan sarana dan prasarana tersebut dapat dilakukan dengan pembelian dan menerima bantuan melalui kontribusi dari guru dan orang tua peserta ujian.

Strategi yang dilakukan untuk mengatasi kekurangan komputer di sekolah ini adalah dengan meminta kesediaan para guru untuk meminjamkan laptopnya untuk pelaksanaan UNBK. Pada tahun 2017, sekolah meminjam 57 unit laptop guru dan selebihnya meminjam kepada orang tua siswa sejumlah kurang lebih 100 unit laptop. Untuk pelaksanaan UNBK pada tahun 2018 dan 2019, pihak sekolah sepenuhnya meminjam kurang lebih 120 unit kepada orang tua siswa dengan cara memberikan izinkan anaknya untuk membawa laptop ke sekolah guna melaksanakan UNBK. Pendistribusian sarana dan prasarana UNBK menggunakan empat ruang dengan kapasitas jumlah komputer/laptop 35-40 unit dengan cadangan. Hal ini pun sesuai dengan keterangan bahwa untuk satu server lokal dengan 40 client. Peserta UNBK dalam tiap ruangan berjumlah 35-36 orang siswa.

\section{Strategi Bidang Sumber Daya Manusia}

Untuk UNBK, proses perekrutan proktor dan teknisi mengacu pada kriteria persyaratan bahwa mereka harus memiliki pengetahuan atau kompetensi dalam bidang teknologi informasi dan jaringan. Dalam pelaksanaan UNBK di sekolah ini, proktor utama dan teknisi utama dibantu oleh empat proktor di setiap karena terdapat empat ruang tempat pelaksanaan UNBK. Setiap ruang dibantu oleh teknisi atau anggota panitia untuk membantu tugas proktor ruang dalam proses pengerjaan soal UNBK oleh peserta ujian.

\section{Strategi Bidang Kesiswaan}

Berbagai upaya yang telah dilakukan oleh pihak sekolah untuk menyiapkan siswa menghadapi UNBK. Dalam rangka persiapan ujian sekolah berstandar nasional (USBN) dan UNBK Tahun Pelajaran 2018/2019, pihak sekolah melaksanakan program pengayaan bagi peserta didik kelas IX. Pengayaan dilaksanakan sejak awal Januari 2019 sampai dengan bulan Maret 2019. Tujuan pelaksanaan pengayaan ini untuk meningkatkan dan memantapkan kompetensi peserta didik serta kesiapan mereka untuk menghadapi ujian USBN dan UNBK baik dari segi penguasaan materi dan kesiapan mental. Pemberian materi pengayaan dengan menggunakan materi 
dari buku Detik-Detik Menghadapi Ujian Nasional. Pelaksanaan pengayaan tersebut tidak dikhususkan pada mata pelajaran untuk UNBK, tetapi untuk semua mata pelajaran termasuk untuk mata pelajaran USBN.

Sementara itu, siswa juga diberikan persiapan menghadapi ujian melalui proses simulasi pra UNBK dilakukan dalam dua tahap, yaitu tahap dua dan tahap tiga. Tahap dua berlangsung selama empat hari sesuai dengan mata pelajaran yang diujiankan seperti bahasa Indonesia, matematika, bahasa Inggris dan ilmu pengetahuan alam. Untuk simulasi bersih atau simulasi tahap tiga hanya berlangsung dua hari dengan mata pelajaran matematika dan bahasa Inggris. Pelaksanaan simulasi pra UNBK ini bertujuan untuk memberikan pemahaman dan bimbingan untuk pelaksanaan Ujian Nasional kepada peserta didik. Selain itu, simulasi diharapkan dapat memberikan kesiapan mental untuk peserta didik dalam menghadapi UNBK.

\subsection{Kendala dalam Menerapkan Ujian Nasional Berbasis Komputer}

Dalam pelaksanaan UNBK di sekolah ini, setiap tahun pihak sekolah selalu mengupayakan agar tidak terdapat kendala berarti baik kendala teknis maupun nonteknis. Meskipun sekolah ini sudah menerapkan UNBK selama tiga tahun terakhir, akan tetapi masih ada beberapa kendala dalam pelaksanaannya. Hasil analisis data menunjukkan bahwa dalam awal pelaksanaan UNBK, sekolah ini mengalami beberapa kendala. Kendala pertama yaitu minimnya sarana dalam pelaksanaan UNBK dengan jumlah komputer dan perlengkapan lainnya, seperti server dan kabel yang belum memadai. Kedua, minimnya bimbingan teknis bagi siswa dalam mengoperasikan komputer. Ketiga, kendala teknis berupa terjadinya pemadaman listrik saat pelaksanaan UNBK serta jaringan lokal yang bermasalah, sehingga waktu pelaksanaan UNBK terlambat dimulai untuk hari pertama.

Untuk mengatasi berbagai kendala tersebut, ada beberapa hal yang dilakukan pihak sekolah sebagai solusinya. Untuk mengatasi permasalahan minimnya komputer, sekolah meminta bantuan orang tua dan siswa untuk membawa laptop masing-masing ke sekolah dan meminjam laptop sesuai kebutuhan. Sementara itu, sekolah membeli kelengkapan lainnya dengan menggunakan dana dari komite sekolah dan orang tua siswa. Untuk mengatasi masalah minimnya bimbingan teknis bagi siswa dalam mengoperasikan komputer, pihak sekolah melaksanakan ujian pra UNBK atau simulasi pra UNBK yang dilaksanakan selama dua hari. Terkait kendala teknis seperti masalah pemadaman listrik, pihak sekolah tidak dapat 
mengatasinya karena energi listrik cadangan tidak tersedia. Untuk masalah jaringan internet, proktor dan teknisi melakukan upaya perbaikan hingga jaringan stabil kembali. Oleh karena itu, pelaksanaan UNBK tahun 2018 dan 2019 berjalan dengan lancar.

\section{Pembahasan}

Penelitian ini menunjukkan bahwa strategi kepala sekolah dalam pelaksanaan UNBK sangat penting. Hal ini tidak terlepas dari kenyataan bahwa dalam pelaksanaan UNBK terdapat beberapa prasyarat yang harus dipenuhi oleh sekolah. UNBK hanya diselenggarakan pada sekolah yang sudah siap baik dari infrastruktur, sumber daya manusia, peserta, maupun sarana dan prasarana (Pernamawati, dkk., 2021).

Secara umum, kondisi sarana dan prasarana sekolah ini telah memadai untuk penyelenggaraan pendidikan dan pembelajaran meliputi ketersediaan ruang kelas, ruang perpustakaan, laboratorium IPA, laboratorium Bahasa, ruang pimpinan, ruang guru, tempat ibadah, jamban, gudang, ruang sirkulasi, tempat bermain/olahraga, dan ruang konseling. Namun, jika ditinjau dari aspek pelaksanaan UNBK untuk pertama kalinya pada tahun 2017, sarana yang dimiliki oleh sekolah ini masih sangat minim dan belum memadai mengingat minimnya jumlah komputer dibanding jumlah peserta UNBK. Kendala lainnya adalah jumlah server hanya dua, media kabel yang kurang, jaringan internet yang belum stabil, serta tidak tersedianya cadangan daya suplai listrik. Sementara itu, salah satu aspek pendukung keberhasilan pelaksanaan ujian nasional berbasis komputer adalah implementasi yang sesuai dengan indikator pelaksanaan UNBK mulai dari tahap persiapan, tahap pengelolaan dan tahap pelaksanaan (Retnawati, dkk., 2017; Simbolon, dkk., 2019).

Kemudian, untuk pelaksanaan UNBK berikutnya pada tahun 2018 dan 2019, sekolah ini mendapat bantuan sebanyak 20 unit komputer dari pemerintah pusat sehingga bisa memenuhi satu ruang laboratorium komputer dengan total 40 unit komputer, begitupun alat-alat lainnya yang menunjang kelancaran pelaksanaan UNBK. Hal ini sejalan dengan strategi dalam menerapkan UNBK di sekolah sebagaimana yang dipaparkan oleh Retnawati, dkk. (2017). Pada awalnya harus ada upaya untuk menyediakan peralatan elektronik pendukung karena pelaksanaan UNBK ditantang dengan masalah seputar jaringan internet dan pasokan listrik, serta siswa belum terbiasa dengan penggunaan teknologi informasi (Retnawati, dkk., 2017). 
Strategi kepala sekolah merupakan salah satu faktor yang dapat mendorong sekolah untuk mewujudkan visi, misi, tujuan dan sasaran sekolah melalui program-program yang dilaksanakan secara terencana dan bertahap (Hartina, 2018; Juliantoro, 2017). Dalam pelaksanaan UNBK, kepala sekolah perlu melakukan beberapa persiapan. Dalam hal ini, kepala sekolah berperan penting karena ia memiliki peran penting dalam mengatur strategi penyelenggaraan pendidikan, baik yang berkaitan dengan pengelolaan maupun dengan pembelajaran di sekolah yang dipimpinnya (Haryana, 2018). Dalam mengelola pendidikan kepala sekolah berperan sebagai pemimpin, manajer, administrator, dan supervisor, sedangkan dalam pembelajaran kepala sekolah berperan sebagai edukator, karena meskipun mengelola pendidikan, kepala sekolah juga melaksanakan tugas pembelajaran (Juliantoro, 2017).

Hasil penelitian ini menujukkan bahwa strategi kepala sekolah dalam pelaksanaan UNBK terdiri atas beberapa hal, yaitu: strategi bidang sarana, strategi bidang sumber daya manusia dan strategi bidang kesiswaan. Salah satu strategi kepala sekolah dalam pelaksanaan UNBK di sekolah tempat penelitian ini adalah dalam pelaksanaan simulasi pra UNBK melalui kegiatan peningkatan kompetensi siswa. Hal ini sejalan dengan penelitian Negara, dkk. (2017) yang dilakukan di salah satu madrasah swasta melalui kegiatan peningkatan kompetensi TIK guna simulasi UNBK yang berlangsung selama dua tahap. Hal ini bertujuan untuk memberikan penguatan kepada setiap siswa untuk menjalankan aplikasi UNBK. Dengan adanya kegiatan ini maka siswa memahami fungsi setiap tombol aplikasi UNBK, yaitu tombol memulai pengerjaan soal, tombol paket soal, tombol jawaban dan melihat hasil ujian dan siswa mulai terbiasa menggunakan aplikasi UNBK serta telah mampu menjawab soal pada paket soal yang telah dipilih (Negara, dkk., 2017).

Dalam hal aspek kesiswaan, hasil penelitian ini menunjukkan bahwa pihak sekolah secara strategis selalu memberikan motivasi kepada siswa setiap sebelum dan sesudah mengikuti pelajaran. Hasil penelitian ini mendukung penelitian yang dilakukan oleh (Hartina, 2018) di salah satu madrasah tsanawiyah yang menunjukkan upaya kepala sekolah dalam mempersiapkan pelaksanaan UNBK. Selain itu, pihak sekolah juga memberikan fasilitas bimbingan belajar tambahan untuk mata pelajaran yang akan diujiankan yaitu bahasa Inggris, bahasa Indonesia, matematika dan ilmu pengetahuan (Hartina, 2018). Hal ini berbeda dengan pelaksanaan pengayaan yang dilakukan di tempat penelitian ini yaitu fasilitas pengayaaan diberikan bukan hanya untuk persiapan UNBK tetapi juga untuk USBN. 
Pelaksanaan UNBK yang terbilang baru tentu mengalami kendala dalam pelaksanaannya. Penelitian ini menunjukkan pelaksanaan awal UNBK tidak lepas dari beberapa kendala, baik kendala teknis maupun nonteknis. Pelaksanaan UNBK tahun 2018 dan tahun 2019 berjalan dengan lancar tanpa kendala yang serius, kecuali masih terbatasnya jumlah komputer namun bisa diatasi strategi sekolah yang meminta partisipasi orang tua siswa agar mengizinkan anaknya untuk membawa laptop. Kendala yang terjadi hanya pada saat simulasi tahap dua karena terdapat server yang rusak sehingga pihak sekolah membeli server yang baru. Pada simulasi tahap tiga terjadi pemadaman listrik yag diatasi pihak sekolah dengan menyurati pihak PLN bahwa sekolah ini termasuk salah satu penyelenggara UNBK yang kemudian ditanggapi oleh pihak PLN dengan baik dan memberikan jaminan bahwa tidak akan terjadi pemadaman listrik pada saat UNBK berlangsung. Hal yang sama ditemukan dalam penelitian Harmiyuni dan Sailan (2016) di sekolah yang melaksanakan UNBK. Mereka menemukan bahwa sekolah juga mengalami kendala teknis seperti dengan kecepatan jaringan yang lambat, gangguan jaringan saat cuaca buruk seperti hujan, pemadaman listrik, serta serial number yang berubah ketika server lokal terupdate. Akan tetapi pihak sekolah melakukan upaya mengatasi kendala teknis tersebut dengan melakukan kerja sama dengan PLN, Lintas Arta dan Telkom serta penyediaan server lokal (Harmiyuni \& Sailan, 2016). Dengan demikian, UNBK dapat dilaksanakan di seluruh wilayah atau satuan pendidikan bila didukung oleh perangkat komputer dan internet. Agar pelaksanaan ujian berbasis komputer dapat berjalan dengan lancar, satuan pendidikan harus menyiapkan perangkat keras, jaringan internet, dan jaringan lokal komputer.

\section{Kesimpulan}

Hasil penelitian ini menunjukkan bahwa dalam pelaksanaan ujian nasional berbasis komputer pada awalnya pihak sekolah perlu melakukan upaya menyediakan peralatan elekronik pendukung. Pelaksanaan ujian nasional berbasis komputer ditantang dengan masalah internet dan pasokan listrik, serta dengan siswa yang belum terbiasa menggunakan teknologi informasi yang bermafaat. Untuk menghadapi tantangan tersebut, sekolah perlu menerapkan strategi dengan melakukan upaya untuk menyediakan peralatan elektronik melalui kolaborasi dengan orang tua siswa, meningkatkan kurikulum dengan menambah teknologi informasi sebagai subjek sekolah, melakukan kegiatan peningkatan ICT pada siswa. Penelitian ini telah menunjukkan berbagai strategi yang terapkan oleh kepala sekolah dalam 
pelaksanaan UNBK seperti strategi sarana dan prasarana, strategi program sumber daya manusia, dan strategi kesiapan peserta didik untuk pelaksanaan UNBK. Akhirnya, penelitian ini menegaskan pentingnya strategi kepala sekolah dalam pelaksanaan UNBK.

\section{Daftar Pustaka}

Aden, A., Basir, C., \& Kusdaniyama, N. (2020). Pelatihan penalaran matematika jenis soal ujian nasional berbasis komputer (UNBK) jenjang SMP untuk meningkatkan kualitas pengajar dan minat siswa pada bimbingan belajar dan privat matriks. Jurnal Pengabdian Kepada Masyarakat - Aphelion, 1(1), 1-10. DOI: 10.32493/jpka.v1i01.6629

Firmansyah, A. U. (2018). Aplikasi simulasi iji coba (tryout) ujian nasional berbasis komputer (UNBK) tahun 2018. Seminar Nasional Royal (SENAR), 1(1), 111-114.

Harmiyuni, \& Sailan, M. (2016). Persepsi siswa tentang pelaksanaan ujian nasional berbasis komputer di SMK Komputer Mutiara Ilmu Makassar. Jurnal Tomalebbi, 2, 36-42.

Hartina, S. (2018). Upaya kepala madrasah dalam mempersiapkan pelaksanaan ujian nasional berbasis komputer (UNBK) Tahun Pelajaran 2017/2018 di Madrasah Tsanawiyah Swasta Nurul Amaliyah Tanjung Morawa. Skripsi tidak dipublikasi. Universitas Islam Negeri Sumatera Utara.

Haryana, E. (2018). Implementasi manajemen strategik kepala sekolah dalam meningkatkan mutu sekolah. Indonesian Journal of Education Management and Administration Review, 2(1), 223-230.

Juliantoro, M. (2017). Peranan kepala sekolah dalam meningkatkan mutu pendidikan. Al-Hikmah: Jurnal Kependidikan dan Syariah, 5(2), 24-38. DOI: 10.37092/ej.v1i1.88

Meita, N. M., \& Fatoni, A. F. (2020). Kesiapan sekolah dan siswa terhadap pelaksanaan UNBK tingkat SMP sederajat Tahun Pelajaran 2019-2020. Lensa (Lentera Sains): Jurnal Pendidikan IPA, 10(2), 157-171. DOI: 10.24929/lensa.v10i2.122

Miles, M. B., Huberman, A. M., \& Saldana, J. (2014). Qualitative data analysis (3rd ed.). Singapore: SAGE.

Murtadlo, M., Jazuli, A., \& Catur Murti, A. (2019). Perancangan tryout system UNBK untuk SMP berbasis web. Indonesian Journal of 
Technology, Informatics and Science (IJTIS), 1(1), 5-8. DOI:10.24176/ijtis.v1i1.4595

Negara, H. R. P., Santosa, F. H., \& Bahri, S. (2017). Peningkatan kompetensi ICT guna simulasi UNBK siswa MTs Nurul Ihsan Kecamatan Jonggat Kabupaten Lombok Tengah. JMM (Jurnal Masyarakat Mandiri), 1(1), 1-9. DOI: 10.31764/jmm.v1i1.7

Nirmala. (2013). Strategi kepala sekolah di SD Negeri 1 Lampopala Kabupaten Bombana. Skripsi tidak dipublikasi. Institut Agama Islam Negeri Kendari.

Pakpahan, R. (2016). Model ujian nasional berbasis komputer: Manfaat dan tantangan. Jurnal Pendidikan dan Kebudayaan, 1(1), 19-35.

Pernamawati, S., Kritiawan, M., \& Fitria, H. (2021). Analisis SWOT ujian nasional berbasis komputer. Jurnal Manajemen, Kepemimpinan, dan Supervisi Pendidikan, 6(1), 112-123.

Pranata, J., Pitoewas, B., \& Nurmalisa, Y. (2017). Pengaruh pelaksanaan ujian nasional berbasis komputer terhadap motivasi belajar siswa kelas XII di SMAN 9 Bandar Lampung. Laporan penelitian tidak dipublikasi. Universitas Negeri Lampung.

Rahmania, I., Budiono, B., Soenaryo, S. F., Syakur, A., \& Tinus, A. (2020). Implementation of internal quality guarantee system to increase the quality of education in Junior High School 21 Malang. Budapest International Research and Critics in Linguistics and Education (BirLE) Journal, 3(1), 421-432. DOI: 10.33258/birle.v3i1.838

Retnawati, H., Hadi, S., Nugraha, A. C., Arlinwibowo, J., Sulistyaningsih, E., Djidu, H., Apino, E., \& Iryanti, H. D. (2017). Implementing the computer-based national examination in Indonesian schools: The challenges and strategies. Problems of Education in the 21st Century, 75(6), 612-633. DOI: $10.33225 / \mathrm{pec} / 17.75 .612$

Rusmawati, Suryana, E., \& Harapan, E. (2020). Kompetensi manajerial kepala sekolah dalam pelaksanaan ujian nasional berbasis komputer (UNBK) di Kabupaten Banyuasin. Studi Manageria: Jurnal Manajemen Pendidikan Islam, 2(1), 75-92.

Sampebua, M. R., \& Membala, S. B. (2018). Penerapan aplikasi ujian berbasis komputer untuk meningkatkan kualitas pendidikan pada SMP. Jurnal Pengabdian Papua, 2(1), 24-31.

Simbolon, S. D., Kadir, A., \& Nasution, I. (2019). Implementasi ujian 
nasional berbasis komputer (UNBK) di SMA Parulian 1 Medan. Jurnal Ilmu Pemerintahan, Administrasi Publik, dan Ilmu Komunikasi (JIPIKOM), 1(2), 137-144. DOI: 10.31289/jipikom.v1i2.156

Tamala, E. (2019). Manajemen kepala sekolah dalam implementasi Ujian Nasional Berbasis Komputer (UNBK) di SMP Negeri 1 Konawe Selatan. Skripsi tidak dipublikasi. Institut Agama Islam Negeri Kendari.

Wirawan, A. W., Indrawati, C. D. S., \& Rahmanto, A. N. (2017). Pengembangan media pembelajaran kearsipan digital untuk meningkatkan hasil belajar siswa SMK Negeri 3 Surakarta. Jurnal Pendidikan Vokasi, 7(1), 78-86. DOI: 10.21831/jpv.v7i1.12879

Yin, R. K. (2018). Case study research and applications: Design and methods (6th ed.). Singapore: SAGE. 